\title{
Gambaran Klinis dan Radiologis pada Pasien dengan Uji Mantoux Positif di Bangsal Rawat Inap Anak RSUD Tangerang
}

\author{
Haridini Intan S. Mahdi, Darmawan B. Setyanto, Evita B.Ifran \\ Departemen Ilmu Kesehatan Anak FKUI RS Dr. Cipto Mangunkusumo Jakarta
}

\begin{abstract}
Latar belakang. Tuberkulosis pada anak mempunyai permasalahan yang berbeda dengan orang dewasa karena terdapat berbagai permasalahan dalam diagnosis, pengobatan, dan pencegahan. Pemeriksaan penunjang yang dilakukan untuk menegakkan diagnosis tuberkulosis adalah dengan uji tuberkulin, pemeriksaan radiologis, serologi, darah tepi, dan histopatologik.

Tujuan. Mengetahui gambaran klinis dan radiologis anak dengan uji Mantoux positif.

Metode. Studi deskriptif di ruang rawat inap anak RSUD Tangerang selama Juni-September 2007.

Hasil. Penelitian ini mendapatkan 59 pasien dengan uji Mantoux positif dari 150 pasien yang dilakukan uji Mantoux. Gambaran radiologis dada AP/lateral sebagai berikut: 40 limfadenopati, 25 kelainan parenkim, 14 penebalan pleura, 5 efusi pleura, kavitas dan kalsifikasi masing-masing 1 kasus. Gejala sistemik berupa demam tidak tinggi dan lebih dari 2 minggu didapatkan pada 19 dari 59 anak, malaise (47 dari 59 anak), berat badan turun/sulit naik ( 53 dari 59 anak), anoreksia ( 51 dari 59 anak). Batuk lebih dari 2 minggu (20 dari 59 anak) kemungkinan karena tuberkulosis, sedang sesak napas (14 dari 59). Pembesaran kelenjar getah bening merupakan gejala yang tidak khas pada tuberkulosis anak ( 6 dari 59 anak).

Kesimpulan. Indeks tuberkulin pada penelitian ini adalah 59 dari 150 pasien (40\%), gambaran radiologis anak dengan uji Mantoux positif bervariasi, sedangkan gejala klinis dapat overlap dengan penyakit primer yang sedang diderita subjek. (Sari Pediatrì 2008;10(4):250-4).
\end{abstract}

Kata kunci: uji Mantoux, tuberkulosis anak, foto radiologi paru

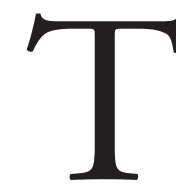

uberkulosis pada anak mempunyai permasalahan dalam diagnosis, pengobatan, pencegahan. Diagnosis tuberkulosis sulit disebabkan gejala umum yang tidak khas,

Alamat Korespondensi:

Dr. Darmawan BS, Sp.A(K) Divisi Pulmonologi Departemen Ilmu Kesehatan Anak FKUI-RSCM Jl. Salemba no. 6, Jakarta 10430.

Telepon: 021-3100669. Fax.021-390 7743 sulit mendapatkan spesimen baik dari sputum maupun bilasan lambung dan nilai uji diagnostik yang rendah. ${ }^{1,2,4}$ Misalnya, seorang anak dapat terkena infeksi tuberkulosis tanpa menjadi sakit, mempunyai uji Mantoux positif tanpa ada kelainan klinis ataupun pemeriksaan radiologis paru dan laboratorium. Pemeriksaan penunjang yang dianjurkan untuk menegakkan diagnosis tuberkulosis yaitu uji Mantoux, pemeriksaan radiologis, serologi, darah 
tepi, dan histopatologik. Diagnosis pasti tuberkulosis adalah dengan ditemukannya kuman tuberkulosis pada pemeriksaan mikrobiologi. ${ }^{2,5}$

\section{Metode}

Penelitian deskriptif untuk mengetahui gambaran klinis, serta gambaran radiologis anak dengan uji Mantoux positif. Populasi terjangkau adalah semua pasien anak yang dirawat di ruang rawat inap anak di RSUD Tangerang sejak 1 Juni 2007 hingga September 2007. Kriteria inklusi adalah semua pasien rawat inap usia 0-18 tahun, uji Mantoux positif, pemeriksaan radiologis dada antero-posterior (AP) dan lateral, serta persetujuan orangtua untuk mengikuti penelitian.

\section{Hasil}

Pengumpulan data dilakukan selama 4 bulan, dari tanggal 1 Juni 2007 sampai 30 September 2007. Selama kurun waktu penelitian, dilakukan uji Mantoux pada 150 pasien dari dua bangsal rawat inap anak dan diperoleh 59 pasien yang memenuhi kriteria inklusi yaitu uji Mantoux positif sebagai subjek penelitian.

Karakteristik pasien dengan uji Mantoux positif dan data sebaran indeks tuberkulin pasien rawat inap dengan uji Mantoux positif tertera pada Tabel 1 dan 2. Gejala klinis pasien dengan uji Mantoux positif bervariasi, seperti tertera pada Tabel 3. Gambar 1 menunjukkan hasil uji Mantoux positif dan tipe indurasi, yang dibagi dalam kelompok turgid dan non turgid. Gambaran klinis pasien dengan uji Mantoux positif tertera pada Tabel 4.

Letak pembesaran kelenjar getah bening pada gambaran radiologis penting untuk mendiagnosis tuberkulosis. Tabel 5 memperlihatkan hubungan antara letak pembesaran kelenjar getah bening pada gambaran radiologis. Profil kelompok umur berdasarkan tipe indurasi uji Mantoux dan pembesaran kelenjar getah bening pada gambaran radiologis tertera pada Tabel 6.

\section{Diskusi}

Usia di bawah lima tahun (balita) 23 (39\%) subjek mempunyai risiko lebih besar terinfeksi sehingga menderita sakit tuberkulosis dibandingkan orang dewasa, dan mempunyai risiko yang lebih tinggi mengalami tuberkulosis diseminata (milier dan

Tabel 1. Karakteristik subjek menurut kelompok usia dan jenis kelamin

\begin{tabular}{ccccccc}
\hline \multirow{2}{*}{$\begin{array}{c}\text { Usia } \\
\text { (tahun) }\end{array}$} & \multicolumn{3}{c}{ Jenis kelamin } & \multicolumn{3}{c}{ Total } \\
\cline { 2 - 7 } & $\mathrm{L}$ & $\%$ & $\mathrm{P}$ & $\%$ & $\mathrm{n}$ & $\%$ \\
\hline $0-<5$ & 12 & 40 & 11 & 38 & 23 & 39 \\
$5-<10$ & 8 & 27 & 12 & 41 & 20 & 34 \\
$10-<15$ & 9 & 30 & 6 & 21 & 15 & 25 \\
$15-18$ & 1 & 3 & 0 & - & 1 & 2 \\
\hline Total & 30 & 100 & 29 & 100 & 59 & 100 \\
\hline
\end{tabular}

Tabel 2. Sebaran indeks tuberkulin

\begin{tabular}{ccc}
\hline Umur (tahun) & Jumlah pasien & Uji Mantoux $(+)$ \\
\hline $0-<5$ & 72 & 23 \\
$5-<10$ & 40 & 16 \\
$10-<15$ & 35 & 15 \\
$15-18$ & 3 & 1 \\
\hline Jumlah & 150 & 59 \\
\hline
\end{tabular}

Tabel 3. Gejala klinis pasien dengan uji Mantoux positif

\begin{tabular}{lcc}
\hline Gejala klinis & $\mathrm{n}$ & $\%$ \\
\hline Demam & 59 & 100 \\
Malaise & 47 & 80 \\
Berat badan turun/ sulit naik & 53 & 90 \\
Anoreksia & 51 & 86 \\
Batuk & 42 & 71 \\
Sesak & 14 & 24 \\
Pembesaran kelenjar getah bening & 6 & 10 \\
\hline
\end{tabular}

Keterangan: satu pasien dapat mengalami lebih dari 1 gejala klinis

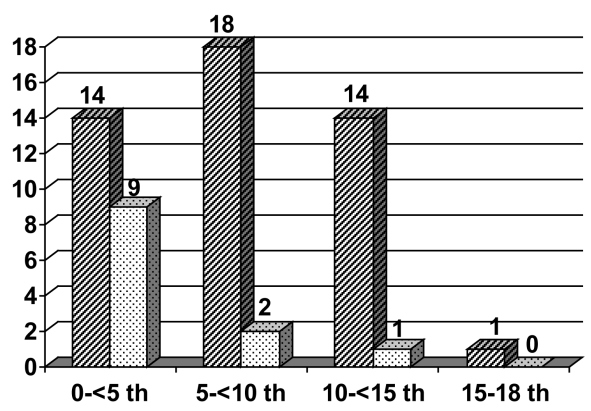

Turgid Non Turgid

Gambar 1. Hasil uji Mantoux positif dengan tipe indurasi menurut kelompok umur 
Tabel 4. Gambaran radiologis pasien uji Mantoux positif

\begin{tabular}{lcc}
\hline Gambaran radiologis & $\mathrm{n}$ & $\%$ \\
\hline Gambaran paru normal/infiltrat minimal & 33 & 56 \\
Infiltrat luas & 17 & 29 \\
Bronkopneumonia & 4 & 7 \\
Gambaran milier & 4 & 7 \\
Atelektasis & - & - \\
Pembesaran kelenjar getah bening & 40 & 68 \\
Kalsifikasi & 1 & 2 \\
Kavitas & 1 & 2 \\
Efusi pleura & 5 & 8 \\
Penebalan pleura & 14 & 24 \\
\hline
\end{tabular}

Keterangan: satu pasien dapat memperlihatkan lebih dari 1 gambaran radiologis

Tabel 5. Karakteristik letak pembesaran kelenjar getah bening berdasarkan gambaran radiologis anak dengan uji Mantoux positif

\begin{tabular}{lcccccc}
\hline \multirow{2}{*}{$\begin{array}{c}\text { Letak } \\
\text { pembesaran } \\
\text { kelenjar getah } \\
\text { bening }\end{array}$} & $\begin{array}{c}\text { Antero- } \\
\text { posterior }\end{array}$ & Lateral & \multicolumn{1}{c}{$\begin{array}{c}\text { Antero- } \\
\text { posterior/ } \\
\text { lateral }\end{array}$} \\
\cline { 2 - 7 } & $\mathrm{n}$ & $\%$ & $\mathrm{n}$ & $\%$ & $\mathrm{n}$ & $\%$ \\
\hline Hilus & 6 & 15 & 10 & 25 & 17 & 43 \\
Paratrakeal & 1 & 2 & 4 & 10 & 2 & 5 \\
\hline Total & 7 & 17 & 14 & 35 & 19 & 48 \\
\hline
\end{tabular}

Tabel 6. Karakteristik tipe indurasi dengan gambaran radiologis pembesaran kelenjar getah bening

\begin{tabular}{lcccc}
\hline \multirow{2}{*}{$\begin{array}{c}\text { Kelompok } \\
\text { umur (tahun) }\end{array}$} & \multicolumn{2}{c}{ Tipe indurasi } & \multicolumn{2}{c}{ Pembesaran kelenjar } \\
\cline { 2 - 5 } & Turgid & $\begin{array}{c}\text { Non } \\
\text { turgid }\end{array}$ & Turgid & Non turgid \\
\hline $0-<5$ & 14 & 9 & 7 & 5 \\
$5-<10$ & 18 & 2 & 12 & 2 \\
$10-<15$ & 14 & 1 & 12 & 1 \\
$15-18$ & 1 & - & 1 & - \\
\hline Total & 47 & 12 & 32 & 8 \\
\hline
\end{tabular}

meningitis tuberkulosis). ${ }^{1,7,8}$ Kerentanan kelompok balita terhadap infeksi tuberculosis karena sistem imun yang belum matur, baik secara kualitatif maupun kuantitatif. ${ }^{10}$

Indeks tuberkulin adalah persentase reaktor per kelompok umur tertentu. Manfaat mengetahui indeks tuberkulin adalah untuk mengetahui besarnya masalah tuberkulosis dalam suatu masyarakat dan selanjutnya dari indeks tuberkulin dapat diketahui ARTI (annual rate of tuberculous infection). ${ }^{8-10}$ Pada awal infeksi, tuberkulosis tidak menimbulkan gejala klinis (hampir 50\% kasus tuberculosis).

Demam merupakan gejala sistemik yang sering menyertai infeksi tuberkulosis berkisar antara 40\%-80\% kasus. Demam tidak tinggi dan hilang timbul dalam jangka waktu lama. Penelitian lain menyebutkan bahwa $21 \%$ pasien tuberkulosis tidak didapatkan demam dan bila didapatkan keluhan demam, lama demam juga bervariasi antara 1-109 hari. ${ }^{3,5}$ Empatpuluh dari 59 subjek mengeluh demam tidak tinggi dengan waktu kurang dari dua minggu. Demam lama (lebih dari dua minggu) didapatkan pada 19 dari 59 subjek, lebih mengarah kecurigaan terhadap tuberkulosis. ${ }^{3}$ Walaupun demam kurang dari 2 minggu dan tidak sesuai dengan gejala tuberkulosis, pada penelitian kami dapat disebabkan oleh penyakit primer lain.

Tuberkulosis merupakan radang menahun dan gejala klinis pada anak sering kali tidak khas. Malaise didapatkan 47 dari 59 subjek. Kepustakaan menyebutkan frekuensi gejala malaise pada tuberkulosis bervariasi sekitar hampir 30\% pasien kelompok usia 0-4 tahun dan 44\% pada kelompok usia 5-14 tahun. ${ }^{6}$ Kepustakaan lain bahkan menyebutkan pada anak dengan tuberkulosis tanpa mengeluh malaise. ${ }^{6}$

Berat badan turun atau sulit naik didapatkan pada $90 \%$ subjek, pada umumnya berat badan pasien tuberkulosis lebih rendah dari berat badan ideal anak sesuai umurnya sehingga menyebabkan gagal tumbuh. ${ }^{6}$ Anoreksia didapatkan pada 51 dari 59 subjek, paling banyak terjadi pada kelompok usia di bawah 5 tahun. Anoreksia merupakan salah satu gejala sistemik tuberkulosis yang mudah ditemukan pada anak di bawah usia 4 tahun dibandingkan pada anak yang lebih besar karena pada anak di bawah usia 4 tahun. Gejala anaroksia pada anak penting sebagai gejala yang harus diamati karena kelompok balita lebih berpotensi menderita tuberkulosis diseminata atau meningitis tuberkulosis.7

Batuk kronik merupakan gejala yang jarang ditemukan pada tuberkulosis anak, karena fokus tuberkulosis primer pada anak umumnya terletak di daerah parenkim yang tidak memiliki reseptor batuk. ${ }^{8}$

Gejala batuk kronik pada tuberkulosis anak dapat timbul bila terjadi limfadenitis regional yang menekan bronkus sehingga merangsang reseptor 
batuk secara kronik. ${ }^{8}$ Batuk lama (lebih dari 2 minggu) didapatkan 20\% pada penelitian kami. Kepustakaan menyebutkan batuk lama didapatkan $40 \%$ pada anak di bawah usia 4 tahun dan anak usia 5-14 tahun terutama pada tuberkulosis paru. ${ }^{3,8}$

Sesak nafas jarang dijumpai kecuali dalam keadaan sakit berat yang berlangsung akut, misalnya pada tuberkulosis milier dan efusi pleura. Sesak napas didapatkan pada $24 \%$ subjek, sesuai dengan kepustakaan didapatkan pada 28\% kasus anak usia di bawah 4 tahun dan 14\% anak usia 5-14 tahun dengan tuberkulosis paru. ${ }^{6}$ Kelenjar limfe superfisialis sering dijumpai dan yang paling sering terkena adalah kelenjar koli anterior atau posterior. Kelenjar yang terkena, pada perabaan multipel, unilateral, tidak nyeri tekan, dan dapat saling melekat. ${ }^{4,8}$

Pembesaran kelenjar getah bening pada anak usia di bawah 5 tahun, bersifat non spesifik, 10\% subjek. Kepustakaan lain menyebutkan bahwa pembesaran kelenjar getah bening pada kasus tuberkulosis anak sekitar 19\% pada anak di bawah usia 4 tahun dan 23\% pada kelompok anak usia 5-14 tahun. ${ }^{6,8}$

Rentang indurasi uji Mantoux didapatkan antara 10-14 mm. Tipe turgid didapatkan lebih banyak pada semua kelompok usia subjek penelitian daripada tipe non turgid. Tipe reaksi uji Mantoux tipe turgid menunjukkan sugestif infeksi tuberkulosis dengan indurasi yang tebal dan lebih lama bertahan. Pada kelompok usia $0-<5$ tahun didapatkan tipe reaksi non turgid lebih banyak dibandingkan kelompok usia lainnya, ada kemungkinan disebabkan oleh reaksi terhadap vaksinasi BCG. ${ }^{6,8}$

Indurasi uji Mantoux $5 \mathrm{~mm}$ dapat disebut positif bila jelas terdapat kontak dengan kasus tuberkulosis dewasa, didapatkan foto dada abnormal, atau seseorang dalam keadaan imunokompremais. ${ }^{8}$ Parut BCG didapatkan hanya 39 dari 59 subjek, dan didapatkan proporsi yang lebih besar pada uji Mantoux yang positif tanpa adanya parut BCG dibandingkan dengan kelompok dengan parut BCG. ${ }^{8}$ Vaksinasi BCG merupakan salah satu dari upaya penanggulangan tuberkulosis dan hingga saat ini pemberian imunisasi BCG masih merupakan bagian dari strategi WHO dan Departemen kesehatan RI dalam menanggulangi masalah tuberkulosis terutama di negara-negara berkembang termasuk Indonesia. ${ }^{8}$

Infeksi atau sakit tuberkulosis harus lebih dicurigai pada anak apabila terdapat kontak erat dengan pasien tuberkulosis dewasa, atau pada anak dengan imunodefisiensi. ${ }^{3-5}$ Kontak positif artinya apabila seseorang anak berhubungan langsung dengan pasien tuberkulosis yang mengandung kuman tuberkulosis di buktikan dengan pemeriksaan bakteri tahan asam (BTA) positif. Data tersebut bermakna dalam menambah kriteria diagnostik. Kontak didapatkan $11 \%$ pada semua kelompok usia subjek sehingga perlu dilakukan pencarian lebih lanjut terhadap kontak tuberkulosis dewasa. Pada awal diagnosis, ditemukan kontak 16\% dan pada pencarian lebih lanjut, ternyata kontak dengan pasien dewasa tuberkulosis aktif sekitar $70 \% .{ }^{5}$ Seorang pasien tuberkulosis dewasa dengan BTA positif dapat menularkan tuberkulosis pada 20 orang di sekitarnya. ${ }^{4,5,28}$ Anak yang mempunyai risiko tinggi terinfeksi tuberkulosis adalah usia balita atau pada masa pubertas terutama di daerah endemis tuberkulosis. ${ }^{5}$

\section{Gambaran radiologis}

Pada seorang anak dengan uji Mantoux positif harus dilakukan pemeriksaan foto radiologis dada anteroposterior dan lateral untuk dapat melihat pembesaran kelenjar hilus atau paratrakeal. Limfadenopati merupakan tanda utama dalam mendiagnosis tuberkulosis primer, sekitar $92 \%$ kasus sedangkan kelainan parenkim $70 \% .^{7,8}$

Gambaran paru normal dijumpai pada 56\% sedang kepustakaan lain mendapatkan 80\%-90\% pada anak di atas usia 1 tahun. ${ }^{8,9}$ Kelainan parenkim paru didapatkan pada $42 \%$ subjek, meliputi infiltrat luas, bronkopneumonia, dan gambaran milier.

Gambaran bronkopneumonia pada tuberkulosis sulit dibedakan dengan bronkopneumonia karena bakteri atau virus. Oleh karena itu hendaknya diperhatikan manifestasi klinis dan pemeriksaan penunjang tuberkulosis yang lain..$^{34,35,59}$ Gambaran foto radiologis dada pada tuberkulosis anak tidak khas, kecuali bila ditemukannya gambaran milier. ${ }^{7,9}$ Gambaran milier didapatkan pada 4 (6\%) subjek pada kelompok usia 0-5 tahun sedikit lebih tinggi dibandingkan kepustakaan lain 3\% kasus. ${ }^{7,9}$

Pembesaran kelenjar getah bening hilus dan paratrakeal didapatkan $68 \%$, lebih sedikit dibandingkan dengan penelitian lain $(92 \%)^{9}$ oleh karena kemungkinan pembesaran kelenjar getah bening akan tampak pada posisi foto tertentu. Kalsifikasi dapat ditemukan setelah terjadi proses perkijuan dari fokus primer. Pada kepustakaan disebutkan bahwa kalsifikasi dapat ditemukan pada 55\% gambaran radiologis ulang setelah 2 tahun. 
7-9 Bila pada gambaran radiologis didapatkan kalsifikasi, harus dibedakan antara tuberkulosis atau keganasan sehingga perlu pemeriksaan penunjang lainnya.

Kavitas hanya terjadi pada anak usia pubertas, yaitu pada tuberkulosis pasca primer. Pada penelitian kami, gambaran kavitas hanya didapatkan pada 1 subjek yaitu dari kelompok usia 10-15 tahun, walaupun kepustakaan menyebutkan bahwa tuberkulosis pasca primer dapat terjadi pada 10\%-30\% kasus tuberkulosis primer. ${ }^{9}$

Keterlibatan pleura pada tuberkulosis didapatkan pada usia lebih dari 5 tahun, dengan manifestasi klinis demam, nyeri dada, dan gejala mirip pneumonia. Efusi pleura jarang terjadi pada usia $<5$ tahun dan terjadi setelah 3-6 bulan terinfeksi tuberkulosis yaitu 25\% kasus terjadi dalam 3 bulan dan $75 \%$ kasus terjadi dalam 6 bulan, sesuai dengan timetable studi Wallgren., ${ }^{8,9}$

Letak pembesaran kelenjar getah bening tuberkulosis anak bervariasi, maka pada anak yang dicurigai menderita tuberkulosis seharusnya dilakukan pemeriksaan radiologis dada dengan posisi anteroposterior dan lateral. ${ }^{6,9}$ Pembesaran kelenjar getah bening pada pemeriksaan radiologis, didapatkan pada 40 dari 59 subjek. Pada kedua tipe indurasi uji Mantoux, dapat ditemukan adanya pembesaran kelenjar getah bening dengan ukuran yang bervariasi. ${ }^{9}$ Tipe indurasi turgid memberikan gambaran pembesaran kelenjar getah bening hilus atau paratrakeal lebih besar daripada non turgid. ${ }^{9}$

\section{Kesimpulan}

Indeks tuberkulin pada penelitian kami adalah 59 (40\%) dari 150 anak yang dilakukan uji Mantoux. Gambaran radiologis dada antero-posterior dan lateral yaitu limfadenopati, kelainan parenkim, penebalan pleura, efusi pleura, kavitas dan klasifikasi. Gejala sistemik berupa demam tidak tinggi dan lebih dari 2 minggu malaise, berat badan turun/sulit naik anoreksia. Pembesaran kelenjar getah bening merupakan gejala yang tidak khas pada tuberkulosis anak.

\section{Daftar Pustaka}

1. Inselman LS. Tuberculosis in children: an update. Pediatr Pulmonol 1996;2:101-20.

2. American Thoracic Society. Diagnostic standards and classification of tuberculosis in adults and children. Am J Respir Crit Care Med 2000;161:1376-95.

3. Rahajoe NN. Tata laksana tuberkulosis pada anak. Sari Pediatri 2001;3:24-35.

4. Fourie PB, Becker PJ, Festenstein F, Migliori GB, Alcaide J, Atunes M, dkk. Procedures for developing a simple scoring method based on unsophisticated criteria for screening children for tuberculosis. Int J Tuberc Lung Dis 1998;2:116-23.

5. Bass JB, Farer LS, Hopewell PC, Jacobs RF, Snider DE. Diagnostic standard and classification of tuberculosis. Am Rev Respir Dis 1990;142:725-35.

6. Starke JR. Tuberculosis in children. Resp Crit Care Med 2004;25:353-64.

7. Smuth NA, Beyers N, Gie RP, Schaaf HS, Talent JM, Nel E, dkk. Value of the lateral chest radiograph in tuberculosis in children. Pediatr Radiol 1994;24:47880.

8. Marais BJ, Gie RP, Scaaf HS, Hesseling AC, Obihara CC, Starke JJ, dkk. The natural history of chilhood intra-thoracic tuberculosis: a critical review of literature from the pre-chemotherapy era. Int J Tuberc Lung Dis 2004;8:392-402.

9. Swischuk LE, John S. Differential diagnosis in pediatric radiology. Dalam: Chest, Mitchell CW, penyunting. Edisi ke-2. Maryland:Williams \& Wilkins;1995.h.1111. 